\title{
Threonine Inhibition of Growth of Bacillus subtilis: Positive Selection for Isoleucine Auxotrophy
}

\author{
By DAVID H. LAMB* AND KENNETH F. BOTT \\ Curriculum in Genetics, and Department of Bacteriology and Immunology, \\ University of North Carolina, Chapel Hill, North Carolina 27514, U.S.A.
}

(Received 4 October 1978)

\section{INTRODUCTION}

Inhibition of microbial growth has often been used as a probe to study the biochemical genetics of autotrophic (Rittenberg, 1969) and heterotrophic (see Ingram \& Jensen, 1973) micro-organisms. To gain insight into the metabolic regulation of growth and sporulation, we have studied the inhibition of Bacillus subtilis by threonine. We found that $8.4 \mathrm{~mm}$-threonine prevented growth and sporulation by restricting valine synthesis and proposed that this restriction was due to an excess of 2-oxobutyrate (derived from threonine) which competed with pyruvate for the active site of acetohydroxyacid synthase (EC 4.1.3.18) thus restricting the flow of carbon into valine (Lamb \& Bott, 1978, 1979). In support of this 'substrate competition' model, we found that most mutants selected for resistance to threonine were auxotrophic for isoleucine and that one of these auxotrophs appeared to be altered in threonine dehydratase (EC 4.2.1.16). It is possible that an isoleucine requirement in the absence of a simultaneous valine requirement is due to an altered threonine dehydratase or an altered isoleucyl-tRNA synthetase (EC 6.1.1.5). Here we report that the majority of threonine-resistant mutants found were auxotrophic for isoleucine irrespective of whether isoleucine was included in the selective medium. In addition, all of the strains auxotrophic for isoleucine that we examined were altered in threonine dehydratase activity.

\section{METHODS}

Bacteria and isolation of mutants. The wild-type strain used was B. subtilis 168 (trpC). All mutants were spontaneously occurring variants and were isolated as described previously (Lamb \& Bott, 1979). Briefly, mutant selection consisted of growing bacteria to mid-exponential phase in Penassay broth (Difco), harvesting by centrifugation, washing once and plating on minimal agar (Spizizen, 1958) which contained (filtersterilized and aseptically added) threonine $\left(20 \mathrm{mg} \mathrm{ml}^{-1}\right)$ and leucine $\left(4 \mathrm{mg} \mathrm{ml}^{-1}\right)$. Resistant colonies were streaked to give single colonies on tryptose blood agar base (Difco) and a single colony was transferred to selective medium. Clones that survived two such cycles of purification were studied further. L-Threonine (allo-free) was A grade from Calbiochem.

Enzyme assays. Threonine dehydratase was assayed by the method of Umbarger \& Brown (1957). Protein was determined by the method of Lowry et al. (1951).

Transformation. Transformations and related procedures have been described by Wilson \& Bott (1968). Genetic linkage between the determinant of the Ile- phenotype of threonine-resistant mutants and the 168 derivative Mu8u5u1 (ile, leu, met, str ${ }^{\mathrm{R}}$ ) was measured by the recombination index method of EphratiElizur et al. (1961). Strain Mu8u5u1 served as recipient for all experiments and selection for $\mathrm{Ile}^{+}$ transformants was made on minimal agar (Spizizen, 1958).

\section{RESULTS AND DISCUSSION}

The term 'threonine resistance' is used to indicate inhibition of growth by a combination of threonine and leucine. Threonine alone caused only transient inhibition of growth in a glucose/salts minimal medium. Consequently, leucine is required for selection of

* Present address: Department of Biological Sciences, Purdue University, Life Sciences, West Lafayette, Indiana 47907, U.S.A. 


\section{Table 1. Threonine dehydratase activity and genetic linkage of several} threonine-resistant mutants

$\begin{array}{lcc}\text { Strain } & \begin{array}{c}\text { Specific activity } \\ \text { of threonine } \\ \text { dehydratase* }\end{array} & \begin{array}{c}\text { Genetic } \\ \text { linkage }\end{array} \\ \text { 168 } & 4.34 & - \\ \text { Thl6 } & 0.31 & 0.09 \\ \text { Thl 10 } & 0.29 & 0.18 \\ \text { Thl 11 } & 0.33 & \text { ND } \\ \text { Thl 17 } & 0.38 & 0.07 \\ \text { Thl 18 } & 0.21 & 0.06\end{array}$

ND, Not done.

* Specific activities are expressed as $\mu \mathrm{mol} 2$-oxobutyrate $\mathrm{h}^{-1}$ (mg protein $)^{-1}$.

$\uparrow$ Values indicate the recombination index between the $\mathrm{Ile}^{-}$phenotypes of the mutant strains and strain Mu8u5u1. In $B$. subtilis, values of $\mathbf{0} \cdot 1$ or less are consistent with the location of two mutations in the same or adjacent genes (see Piggot \& Coote, 1976).

'threonine-resistant' variants and mutants are designated Thl to indicate this. The term 'threonine resistance' appears to be appropriate, however, since leucine merely potentiates the inhibition by threonine but does not alter it qualitatively. This conclusion is supported by the observations that leucine alone does not inhibit growth, valine addition reverses inhibition by threonine plus leucine as it does inhibition by threonine alone (Lamb \& Bott, 1979), and two $\mathrm{Thl}^{\mathrm{R}}$ mutants [Thl 12 (ile) and Thl13 (ile $\left.\left.{ }^{+}\right)\right]$show increased resistance to inhibition of growth by threonine alone (data not shown).

Mutants resistant to threonine appeared spontaneously at a frequency of approximately $10^{-6}$. Most of these $(75 \%)$ were simultaneously auxotrophic for isoleucine. The frequency of isoleucine auxotrophs was not altered if isoleucine was omitted from the selection medium. This observation can probably be explained by the findings of Skarstedt \& Greer (1973) who demonstrated that the threonine synthase (EC 4.2.99.2) of B. subtilis has an associated threonine dehydratase activity. This associated activity would make possible the indirect suppression of mutations in the major biosynthetic threonine dehydratase when large intracellular concentrations of threonine were present.

The finding that high threonine concentrations masked the isoleucine requirement of these strains is consistent, therefore, with the idea that most, if not all, of these strains were defective in threonine dehydratase. To examine this possibility further, several auxotrophic resistant strains were characterized in more detail (Table 1). All mutants examined had low threonine dehydratase activity compared with the parental strain. These mutations also showed close genetic linkage to a known threonine dehydratase mutation (Barat et al., 1965). We conclude that most mutations to threonine resistance are due to alterations in threonine dehydratase. This supports our earlier conclusion that conversion of threonine to 2-oxobutyrate is essential for inhibition of $B$. subtilis by threonine. However, we cannot yet formally eliminate the alternative (but, in our opinion, less likely) possibility that some or all of these mutations conferring isoleucine auxotrophy are regulatory mutations that prevent the synthesis of normal levels of threonine dehydratase. In this context, we have observed that of 22 threonine-resistant mutants selected for the presence of a halo of background growth on selective plates (which often indicates that the resistant strain is overproducing and excreting a compound that can reverse the original inhibition), three were auxotrophic for isoleucine.

The above results imply that selection for threonine resistance may be used as a positive selection for alterations in the $B$. subtilis threonine dehydratase. This observation may be of more than passing interest since recent work has suggested that this enzyme may play an autoregulatory role in the regulation of isoleucine-valine synthesis in B. cereus (Raimond \& Fargette, 1977) and in a variety of other micro-organisms (Goldberger, 1974; Calhoun \& 
Hatfield, 1975). The possibility that the $B$. subtilis threonine dehydratase may play a regulatory role in isoleucine-valine synthesis has not been reported. Leibovici \& Anagnostopoulos (1969) showed that an alteration in the threonine dehydratase of $B$. subtilis conferred sensitivity to valine. This is similar to the findings of Levinthal et al. (1973) who showed that a mutation to leucine sensitivity in Escherichia coli was due to an altered threonine dehydratase and that this strain also showed altered regulation of isoleucine-valine synthesis. These observations, taken together, are consistent with the possibility that threonine dehydratase may play a regulatory role in isoleucine-valine synthesis in B. subtilis but are not, in themselves, sufficient to prove that such a role exists.

This work was supported by grant GM 07092 from the Institute of General Medical Sciences (U.S.A.).

\section{REFEREN CES}

Barat, M., Anagnostopoulos, C. \& Schneider, M. (1965). Linkage relationships of genes controlling isoleucine, valine and leucine biosynthesis in $B$. subtilis. Journal of Bacteriology 90, 357-369.

Calhoun, D. H. \& Hatfield, G. W. (1975). Autoregulation of gene expression. Annual Review of Microbiology 29, 275-299.

Ephrati-ElizUR, E., SRinivasan, P. R. \& ZamenHOF, S. (1961). Genetic analysis, by means of transformation, of histidine linkage groups in Bacillus subtilis. Proceedings of the National Academy of Sciences of the United States of America 47, 56-63.

GoldBERGER, R. F. (1974). Autogenous regulation of gene expression. Science 183, 810-816.

InGRAM, L. O. \& Jensen, R. A. (1973). Growth inhibition by L-phenylalanine in Agmenellum quadruplicatum. A clue to some amino acid relationships. Archiv für Mikrobiologie 91, 221233.

LAmB, D. H. \& BotT, K. F. (1978). Threonine inhibition of vegetative growth and sporulation in Bacillus subtilis. In Spores VII, pp. 299-303. Edited by G. Chambliss \& J. C. Vary. Washington, D.C.: American Society for Microbiology.

LAMB, D. H. \& BotT, K. F. (1979). Inhibition of growth and sporulation of Bacillus subtilis by threonine. Journal of Bacteriology 137, 213-220.

Leibovici, J. \& ANAGnostopoulos, C. (1969). Properties de la thréonine désaminase de la souchs sauvage et d'un mutant sensible a la valine de Bacillus subtilis. Bulletin de la Société de chimie biologique 51, 691-707.

Levinthal, M., Williams, L. S., Levinthal, M. \& UMBARGER, H. E. (1973). Role of threonine deaminase in the regulation of isoleucine and valine biosynthesis. Nature New Biology 246, 65-68.

Lowry, O. H., Rosebrough, N. J., FARr, A. L. \& RANDALl, R. J. (1951). Protein measurement with the Folin phenol reagent. Journal of Biological Chemistry 193, 265-275.

Piggot, P. J. \& CoOte, J. G. (1976). Genetic aspects of bacterial endospore formation. Bacteriological Reviews 40, 908-962.

Raimond, J. \& Fargette, F. (1977). Regulation de la biosynthèse de isoleucine, valine chez Bacillus cereus $\mathrm{T}$ : role possible de la thréonine desaminase. Comptes rendus hebdomadaire des séances de l'Académie des sciences 284, 2301-2304.

RitTEnberG, S. C. (1969). The roles of exogenous organic matter in the physiology of chemolithotrophic bacteria. Advances in Microbial Physiology 3, 159-196.

Skarstedt, M. T. \& Greer, S. (1973). Threonine synthetase of Bacillus subtilis. The nature of an associated dehydratase activity. Journal of Biological Chemistry 248, 1032-1044.

SPIZIZEN, J. (1958). Transformation of biochemically deficient strains of Bacillus subtilis by deoxyribonucleate. Proceedings of the National Academy of Sciences of the United States of America 44, 10721078.

UMBarger, H. E. \& Brown, B. (1957). Threonine deamination in Escherichia coli. II. Evidence for two L-threonine deaminases. Journal of Bacteriology 73, 103-112.

Wilson, G. A. \& BotT, K. F. (1968). Nutritional factors influencing the development of competence in the Bacillus subtilis transformation system. Journal of Bacteriology 95, 1439-1449. 